\title{
Super Responsive Supply Chain: The Case of Spanish Fast Fashion Retailer Inditex-Zara
}

\author{
Md Afzalul Aftab ${ }^{1}$, Qin Yuanjian ${ }^{1}$, Nadia Kabir $^{2}$ \& Zapan Barua ${ }^{1,3}$ \\ ${ }^{1}$ School of Management, Wuhan University of Technology, Wuhan, P. R. China \\ ${ }^{2}$ Department of Pharmacy, University of Asia Pacific, Dhaka, Bangladesh \\ ${ }^{3}$ Department of Marketing, University of Chittagong, Chittagong-4331, Bangladesh \\ Correspondence: Zapan Barua, Department of Marketing, University of Chittagong, Chittagong-4331, \\ Bangladesh; School of Management, Wuhan University of Technology, Wuhan, China. E-mail: zapan@cu.ac.bd
}

Online Published: April 22, 2018

doi:10.5539/ijbm.v13n5p212

URL: https://doi.org/10.5539/ijbm.v13n5p212

\begin{abstract}
The successful implementation of an integrated supply chain strategy enhances total control over the operations and thus enhances speed and flexibility. The objective of this study is two-fold: first to identify the constituents that mold the fast fashion retailing business model, and second to discuss how global leader of fast fashion retailing Inditex-Zara's product offering is strongly supported by integration of various supply chain operations. The findings suggest that vertical integration through ownership of various operational stages including product design and development, production operation, logistics and distribution channel; appropriate sourcing strategy to meet product needs; application of process/product modularity practices in product design, material procurement and manufacturing to ensure manufacturing flexibility; flexible logistics capability; and all of these seamlessly integrated and coordinated by a centralized IT infrastructure can significantly raise overall supply chain flexibility and responsiveness. Inditex-Zara's super-responsive supply chain reduces 'bullwhip effect', order-to-delivery lead time to stores, ensures lean inventory and high level of responsiveness to adapt and deliver products to stores with latest fashion trends and customer feedbacks at a rapid speed. Thus Inditex-Zara is able to successfully counter the negative effects of short product life cycles, high product variety, demand uncertainty and thus able to closely match product supply to the stores with market demand. This contributes to lower inventory backlogs; avoid mark-down losses and/or inventory stock out.
\end{abstract}

Keywords: fast fashion retailing, flexibility, modularity, responsiveness, sourcing strategy, supply chain, vertical integration, Inditex-Zara

\section{Introduction}

Traditional fashion buying in the clothing industry is directed by a fixed calendar of trade fairs, fashion shows, fabric events etc., organized around a 2-season approach to product ranges e.g. Spring-Summer and Fall-Winter. Previous sales data is the basis for the planning of product ranges i.e. forecast driven, starting as long as one year in advance of the selling season (Birtwistle, Siddiqui, \& Fiorito, 2003). The traditional product development/design cycle is long (several months to over a year) and manufacturing process is burdened with long lead times. Retailers following traditional fashion buying have lower product variety but are able to take advantage of scale economies in material procurement and product manufacturing (Venkatesh \& Swaminathan, 2004). However fashion companies have been forced to abandon the planned seasonal product and embrace creating smaller collections more frequently due to diversity in consumer lifestyle and consequent demands for newness and uniqueness. This suggests that products' life cycles have shortened, product varieties have significantly increased and forecast accuracy for demand has fallen to lower levels (Christopher, Lowson, \& Peck, 2004). It can be argued that firms that keep following the traditional fashion buying and release planned seasonal product will accrue significant market mediation costs and therefore will put an adverse impact on their profit margins. For instance with lower forecast accuracy, the retailer may raise the inventory level for all types of finished goods to meet required customer service level or the inventory held may be below the actual demand. This may either turn out into higher inventory holding cost or larger product end-of-life write-offs due to high risk of obsolescence or into lost sales opportunities due to under stock. McCutcheon, Raturi, and Meredith (1994) through a case study found that an organization may lose market share to competitor if the organization is 
incapable to satisfy the demand for product variety in a cost-effective manner while its competitors can. The Spanish fast fashion retailer Inditex-Zara broke the 2-season paradigm i.e. planned seasonal product and started to create smaller collections more frequently resulting in as many as 20 "seasons" per year (Christopher et al., 2004). This has been facilitated by developing and establishing a super-responsive supply chain known as 'Rapid-Fire Fulfillment' with the ability to compress product design-production-delivery cycle lead time within 15 days (Ferdows, Lewis, \& Machuca, 2004). Zara is able to replenish products rapidly driven by customer demand and also offers frequent assortment rotation of products in stores. The purpose of this paper is to document and map out a comprehensive view of Inditex-Zara's unique operating model and many of its best practices in supply chain operations covering processes including development process of new product design, tightly integrated information system that facilitates data feedback from retail stores to each of their business units, order/offer process, postponement at the material procurement and processing stage, internal manufacturing and outsourcing decisions, distribution and retailing (i.e. brick and mortar stores and on-line stores). Mapping out the operations process was deemed necessary to explain how these adopted key practices enabled Inditex-Zara's successful quick-response supply, production, and retail network to attain 'world-class' supply chain management. We try to explain how Zara's integrated approach to supply chain management optimizes the entire chain instead of focusing on singular parts. Zara's holistic approach has significantly enhanced its competitiveness to respond to the fast changing nature of fashion apparel industry and fulfill customer satisfaction through rapid responsiveness while also satisfying supply chain performance objectives. The unit of analysis in this paper is Inditex-Zara, pioneer and global leader of fast fashion retailing also categorized as branded manufacturer in the buyer driven clothing value chain (Gereffi \& Frederick, 2010). The findings may be insightful to executives of manufacturer-retailer firms; case study in business academics; and for developing research tools (i.e. survey questionnaire) for performing further research. The paper has considerable practical significance in that, the comprehensively mapped out view of the supply chain operations can be replicated by others to gain competence in their operations. The paper is organized as follows: section 2 discusses the adopted research methodology. Section 3 discusses Inditex-Zara's introduction, its fast fashion product offering strategy, rapid responsiveness and resultant competitive advantage. Inditex-Zara's offer/order process of merchandise for delivery to retail stores is discussed in Section 4. Section 5 discusses about internalized design phase and design development process for the total product line. Postponement application in fabric procurement phase and production operation decisions (i.e. internal manufacturing and outsourcing) are discussed in sections 6 and 7. Sections 8 and 9 discuss Inditex-Zara's distribution and retail operations. Section 10 discuses a framework illustrating Inditex-Zara's integrated operations and product/information flow across the value chain and finally conclusion is discussed in section 11 .

\section{Research Methodology}

The research problem addressed in this paper can be answered in the real-world managerial context more effectively and as such qualitative research methodology has been adopted (Mintzberg, 1979). Case study research approach, a subcategory of qualitative research method is particularly well suited to little known, under-researched and relatively new phenomenon where no previous theory exists or research areas where existing theory seems insufficient to explain the phenomenon (Eisenhardt, 1989; R. K. Yin, 2009). Real-case phenomena captures the reality of a given situation in substantial detail in order to have a deeper understanding of the phenomena and gain 'how' and 'why 'insights (Yin, 2003). Problem-solving, processes, and organizational functions may all be studied utilizing case research approach. This study adopted single-case design with single unit (R. K. Yin, 2004). According to Yin (2004), the case chosen for single case study should be such that it is a representative one and allows capturing and describing the characteristics of other firms operating in the same industry. An in-depth single case analysis of Inditex-Zara a Spanish fast fashion retailer has been done to map out the adopted supply chain process that enable it with capabilities such as simultaneously maintaining unprecedented lead-times, high fashion content, and low price and thus become global leader in the fast fashion retailing business. The main data sources used to run this in-depth single case analysis of Inditex-Zara were review of various published case studies, articles and thesis; blogs and online news articles; company annual reports (2014-2017) and company website.

\section{Inditex-Zara's Fast Fashion Product Offering}

Zara the pioneer and global leader in fast-fashion retailing was founded by Ignacio Amancio Ortega in Galicia, Spain in year 1975 (Ferdows et al., 2004). Zara is the flagship business unit of the 8 total chains controlled by the holding company called Inditex. Inditex (acronym for Industria de DisenoTextil, S.A.) is a Spanish multinational clothing company headquartered in Arteixo, Galicia, Spain and in addition to Zara also owns the chains namely Zara Home, Massimo Dutti, Bershka, Oysho, Pull and Bear, Stradivarius and Uterqüe. During the 
first half of year 2017, Inditex had 7,405 stores, while its online platform was operating in 45 countries covering a total of 94 markets (Inditex Annual Report, July, 2017). Inditex delivers about 50,000 distinct new items per year in thousands of stores worldwide compared with 2,000-4,000 items in stores for its key competitors (Inditex Annual Report, 2017). During year end of 2016, Inditex's net sales reached 23.311billion Euros (Inditex Annual Report, 2016) and stock market capitalization valued at 95.167 billion euros. The fast fashion retailer Zara that constitutes over $66 \%$ of Inditex's business has a global reach in total of 94 markets encompassing 2,236 physical stores during the first half of year 2017 (Inditex Annual Report, 2017), while its e-commerce stores operated in 45 nations (Inditex Annual Report, 2017). During year end of 2016, Zara's net sales reached 15.394 billion Euros (Inditex Annual Report, 2016).

Zara targets a general industry-wide mass market rather than a luxurious segment in the industry. Zara's "fast fashion" puts emphasis on providing products that contains the latest and most trendy fashionable design concepts manufactured in distinctive types of styles, materials, colors, and silhouettes with reasonable physical quality rapidly and at very attractive prices. Such products are categorized as fashion products (Doeringer \& Crean, 2006). New styles can emerge all of a sudden (based for example, on what a celebrity put on during a televised television program), its demand surge in popularity and then quickly fade away before the end of a particular season which apparently makes "fashion misses" a common phenomenon. This makes demand for fashion apparel product to be highly unpredictable and thus suggesting lower forecast accuracy (Abernathy, Volpe, \& Weil, 2006). Additionally, since fashion product category has a rapid pace of changing styles, it results in short product life cycle of 1 month or less (Doeringer \& Crean, 2005). High demand unpredictability and short lifecycle makes fashion category apparel products extremely time sensitive but not so price sensitive (Fisher, 1997). Zara compares the fashion apparel business to selling fish. When it's fresh, it sells quickly and at a high price; the older it becomes, the harder it is to sell and often requires discounting (The Economist, 2012). The retail giant Zara capitalizes on this problem by rapid responsiveness to the emerging new styles. Zara can bring a new product from concept-design-production-store shelves in as little as 3 weeks compared with industry standard for design-to-retail cycle for luxury brands of 5-6 months (Inditex Annual Report, 2017). Zara introduces new products in huge variety or replenish existing successful products belonging to the high fashion category in small quantities in each twice-weekly shipment. Products are not mass produced in terms of same color and style but are differentiated to the extent that each customer feels of wearing a one of a kind style. Products sold across the world is not confined to a specific region's taste rather is diverse by being inclusive of global trend. About $3 / 4^{\text {th }}$ of the merchandise on display is changed every 3-4 weeks (Ghemawat \& Nueno, 2006). Thus Zara is able to offer customers with exclusivity in their rapidly changing fresh assortments of product lines. Through consistent introduction of new fashionable items, Zara has developed brand image for being cutting edge, trendy, and highly fashionable retailer (Abernathy et al., 2006). McAfee, Sjoman, \& Dessain, (2007) noted that Zara attires are not produced to be "classics" (i.e. attires that would always be in trend) but rather to have reasonably shorter life cycle, both within retail store product offerings and inside clientele's wardrobes. Zara clothes are not designed and manufactured to be long lasting as they are made with less expensive fabric and are characterized as "clothes to be worn 10 times". Zara also offers basic category apparel products that constitute $40 \%$ of its product assortment vs. H\&M's 70\% (Caro \& Martínez-de-Albéniz, 2015). The simple basic style apparel products contain low fashion content, come in few classic colors, and have product life cycle of 2-3 years with little seasonal variation that sell all year round e.g. men's and children's merchandise such as sweater, dress shirts. Basic style apparel products have a stable demand pattern and can be forecasted with higher accuracy (Doeringer \& Crean, 2006; Ghemawat \& Nueno, 2006; Warburton \& Stratton, 2002). Ferdows et al. (2004) noted that Zara's product lines are segmented into women's, men's, and children's, with additional segmentation of the women's line into three sets of offerings that varies in terms of their prices, fashion content, and age targets. This is because women collection line is more fashionable, moves at a very high speed and constitutes Zara's core business. As such women collection lines are positioned in the most strategic places and often at the front part of the stores. In addition to the three product families belonging to apparel items, Zara also sell footwear, lingerie, accessories, cosmetics, and fragrances in its retail stores (Chu, 2005).

Mazaira, González, and Avendaño (2003) found that Zara avoids the industry standard cost-plus margin pricing policy and instead first identifies the prices customers are willing to pay and also the price of similar products offered in competitors' stores. Then, the company establishes target prices for each of its specific items, often $15 \%$ below those of competitors (Crofton \& Dopico, 2007). The information is provided to the company purchasing department, who are in charge of margin control. Purchasing department then controls the cost of production (i.e. in terms of costs for material and supplier) so that desired price and margin can be achieved (Mazaira et al., 2003). Merchandises are sent to stores in small shipments, display shelves are sparsely stocked, individual items to be sold are on display for no longer than a month and assortment of products in stores are frequently rotated 
all of which help to create an ambience of scarcity and opportunity (Crofton \& Dopico, 2007). Zara has estimated that, an average Zara customer visits the chain 17 times a year, compared with an average of 3-4 times a year for competing chains (Ferdows et al., 2004). Since Zara can offer a huge variety of the latest designs rapidly in affordable prices and supplies to stores in limited quantities it can successfully counter "strategic consumer behavior" where customers delay purchasing of products until products are marked down and encourage consumers to buy the products at full price. Thus Zara has 12 inventory turns per year compared to 3-4 per year for competitors and is able to sell 85 percent of its entire product range at full price compared to the industry average of selling only 60-70 percent of items at full price (Crofton \& Dopico, 2007).

Zara's product mark down used to be a problem since country managers had a tendency to focus on liquidating stock rather than maximizing revenues, which arose from the pressure to open up space for the incoming season. The I.T department of Zara developed a model to optimize mark-down during clearance sales in 2008, which provided suggestions on when to markdown aggressively and when it was better to postpone product markdown. The model resulted in significant increase in revenues. Annually Zara has $10 \%$ of inventory that remains unsold compared to industry averages of $17-20 \%$. Items that remain unsold after 2 weeks of their introduction are returned to the distribution center and are disposed of through a separate chain of stores (Ghemawat \& Nueno, 2006). Inditex's high level of flexibility in its operations, allows performing manufacturing of its high margin fashion category apparel products based on the more accurate short-term (2-6 week) demand forecasts instead of relying on inaccurate long-range sales forecasts (6-12 months). This contributes to lower inventory costs and mark-down losses and yet continues to 'saturate' stores with new products (Tokatli, 2008). Zara commits production of only $15-39 \%$ of a season's line 6 months in advance of a season's line (versus the $80-90 \%$ done by competitors) and introduces these new design collections at the beginning of the fall/winter and spring/summer fashion periods. Zara designs and produces $50-60 \%$ of its line versus the industry average ranging from practically zero to a maximum of $20 \%$ during the start and middle of the season, changing the colors, cuts, and fabrics of existing designs in response to customer feedbacks as well as adding completely new ones making introduction of new items a continued process throughout the year (Amed \& Abnett, 2015; McAfee et al., 2007). Inditex- Zara has developed responsiveness and competitive advantage in the market through coordination and tight integration of various operations related to design creation process, material sourcing, offer/order process, production, distribution process and sales through brick-and-mortar retail stores or online stores and make them work seamlessly. Most of these processes are vertically integrated i.e. owned by Zara thus giving complete control over its product (Chu, 2005). In the following sections we discuss each of these operations in details and also develop a model illustrating the product flow and information flow in the integrated processes.

\section{Offer and Order Process of Merchandise for Retail Stores}

Mcafee, Dessain, and Sjoman (2007) discussed how 'offer' and 'order' process for merchandise are prepared disseminated and executed. At the beginning of each season, a commercial within the design team communicates order information to manufacturing plants in the form of a first-production request and sends the produced new collections to the stores. Each store is sent about 25,000 units within a 2-week period. But once new products arrive at the stores, it is responsibility of the section managers to order replenishments. All Zara stores have technologically similar handheld computers known as personal digital assistants (PDAs) which are used for transmitting order and offer information consisting of large amount of minute stock-keeping unit (SKU) level data to and from headquarters to all the retail stores around the world and also for functions such as managing product returns to the distribution centers. Applications developed by Zara's I.T department are used to prepare the distribution of "offer" from head quarter to stores worldwide and receipt and aggregation of "order" from stores to headquarter over the Internet. The use of PDA instead of fax machines in performing the critical ordering process, twice a week saves Zara both cost and delay. The ultimate result is reduced lead-time in the ordering process. Twice a week approximately 24 hours before each order deadline, each store manager receives a morning "offer" in his/her handheld computers known as personal digital assistants (PDA). The offer lists the products that the logistics center has in stock with descriptions, photos of the newly available items, and a history of how many of that product the store has already received and sold. Offers are developed by a team of commercials and are based on availability of garments, patterns of regional sales, predictions about what would sell well in each location and other important factors making each region's offer to be unique. To expedite and simplify ordering, the store manager divides the offer into segments and "beames" each segment to the handheld devices of the section managers for product lines of Men, Women, and Children using infrared technology. Section managers use these data along with their own judgement of customer demand and their knowledge of store inventory to decide how many units of each item to order. The IT system on any in-store computer does not provide store-inventory data and so section managers can know store's inventory stock levels by spending most 
of their time on the selling floor. Each section manager using their handheld device fills in their part of the offer as they explore through the store, and send their part back to the store manager. Store managers after evaluation sends the completed form, now called "the order," back to head quarter at the pre-designated day and cut-off time for order placement, twice a week. Zara places very strict restrictions on the deadline for order placement. If a store slips its deadline, it has to wait until next time (Ferdows, Lewis, \& Machuca, 2003) and head quarter in La Coruña calculates a replenishment-only order for them based on what they had sold since the previous order and sends inventories accordingly (McAfee et al., 2007).

Another application aggregates "the order" sent from each store at the SKU level and compares to available total supply of inventory for each SKU in the distribution center. In cases supply matched demand for a particular SKU, the application simply allocates the inventory according to specific store's order requirement. In cases when supply and demand are imbalanced, the application highlights the situation and executes commercials' decisions about how to allocate products. These commercials at headquarter also known as "country manager" are in charge of order fulfillment by controlling the flow of product to stores. Their responsibility is to match the supply of finished clothes coming from factories worldwide into the distribution center with the stores' demand for these pieces. They work with two categories of information: the aggregated orders from all stores which are finalized soon after the order deadline has passed and the total supply of inventory in the distribution center at the same point in time. Both these types of data are at the SKU level. They are assisted by computer algorithms, developed in partnership with Massachusetts Institute of Technology, which help to get the right mix of sizes for stores. However, the commercials still have the independence to adjust everything manually, depending on local feedback and market knowledge. These commercials or country managers gather information at multiple levels of aggregation. In addition to analyzing sales data, they also talk to regional managers to get an aggregated view of regional trends and with store managers to get crucial information on what their customers like, dislike, and request, as well as feedback on how new items are selling. Most country managers have worked in stores, often as managers, so they know the right questions and understand the answers when speaking to regional managers (Sull \& Turconi, 2008). In times when demand for an SKU exceeds supply the commercials prioritize the stores with supplying the available inventory that had been most successful at selling the item. To decide upon the future production requirements for each SKU, these commercials collaborate with the product managers. Production could be immediately increased by placing replenishment requests if demand exceeded supply. And production could be stopped by decreasing replenishment requests and eventually halt forwarding fresh factory orders altogether in cases supply exceeded demand. Finally, commercials also ship new items in limited quantity to certain key stores in targeted geographies for which they want to assess demand. If consumer reactions are unambiguously positive, the items are produced on a larger scale and stocked up in the two weeks. And when the items turn out to be unpopular, the limited initial inventory minimizes the resulting markdowns (Ghemawat \& Nueno, 2006; Sull \& Turconi, 2008). When commercials find that garments selling slowly in one area are popular in another area, they can trigger store-to-store product transfers (McAfee et al., 2007).

Caro and Martínez-de-Albéniz (2015) noted that previously, there were two problems in Zara's inventory allocation process. First since the store manager's remuneration was dependent to total sales in the stores, there was an inclination for store associates to order quantities exceeding their true weekly requirements, specifically when they assumed that the inventory level of a popular selling item could be in limited supply at the distribution center. Secondly, Zara put merchandise on display only when the complete set of sizes for a merchandize was available. Otherwise the merchandise would be put out of display area. Therefore ensuring that a complete set of products were available in the store at every point in time was a complicated rationing problem that needed to be performed by the inventory allocation operation team for thousands of products in just a few hours. In 2005, Zara developed and adopted a new allocation process mechanism based on formal forecasting and optimization models. Two categories of information including past sales data and order information of store managers are fed into the forecasting and optimization model that could maximize sales in the stores while incorporating inventory availability and the display policy regarding sizes. The utilization of analytical models, also known as Operations Research, focused on finding the global optimum for the chain rather than many local optima for individual stores and helped to create a scalable process with consistent allocation rules. The new mechanism was able to allot inventory where it was most required and was able to ship specific sizes only where it was likely to generate sales. Overall, sales increased by approximately 3-4\% (Caro \& Martínez-de-Albéniz, 2015).

\section{Zara's Internalized Design Phase}

Ferdows et al. (2004) posited that Zara's single, centralized design and production center is linked to the Inditex headquarters in La Coruna with an area of $1.7 \mathrm{~m} \mathrm{sq} \mathrm{ft}$. Zara's design center consist of 3 spacious halls each dedicated to clothing lines for women, men, and children. Each clothing line is operationally distinct because 
separate design, sales, procurement and production-planning staffs are dedicated to each. Though it's more costly to operate three different channels, the information flow for each channel is swift, direct, and free from inaccuracy thus profoundly increasing the responsiveness of the overall supply chain. At Inditex, the design teams consist of 700 highly talented designers who translate the desires of customers into the fashion (Inditex Annual Report, 2017). In addition to raw creativity, these designers also need attention to detail, analysis, instinct, insight and simple human empathy.

\subsection{Designers Are Co-Located}

Omera, Christopher, and Creazza (2012) suggested that when there is low coordination between designer team and other members of supply chain like buying team, merchandizing team, pattern-makers and suppliers it often causes delay in range planning for new collections thus increasing product development lead time and choking responsiveness. This situation can be solved by co-locating them so as to enable cross functionality and thus high coordination. As such they can have increased product knowledge and can streamline the product design decision making process. The team can use standard frameworks and process mapping which can quickly be communicated across the supply chain. Both the velocity and quality of design process is enhanced as design process is managed in coordination with other functions in the supply chain. Sull and Turconi, (2008) discussed how at Inditex, its design team, commercial team, market specialists, procurement teams and production planners work in tightly synchronized teams at headquarters.

\subsection{Design Development Process for New Products}

It is absolutely necessary to foresee fashion trends and fickle consumer preferences in the rapidly changing fashion industry. McAfee et al., (2007) noted how sales associates and section managers at the stores keep track of customer's feedback on different product lines, popular items and also try to identify patterns in terms of item, style and color that customers look for and update the store managers with these patters. At Zara stores unlike competitors, floor staffs do not court customers or provide formal fitting services, rather work on displaying freshly arrived products quickly and effectively. Zara generally employs young fashion-conscious staffs in the retail stores that pay meticulous attention to identify local trends from media or public places. Store managers worldwide use customized handheld digital devices to quickly and accurately exchange market data such as sales trends broken down by style, color and size and use phone conversations or visits headquarters (only key store managers) to continuously communicate the detected patterns with a group of commercials known as store product managers or commercial-sales specialists. These commercials have great acumen in determining what clothes would be designed and manufactured and decide possible price points for products. Commercials could also create, extend and modify collections. Each team of commercials is dedicated to a section of the store (Men, Women, or Children). These commercials serve as head quarter's main interface with network of retail stores worldwide by working in proximate office spaces to the product teams. Product teams usually consist of two designers, one procurement planner responsible for purchasing material and one production planner responsible to place production orders with the factories. Primary estimation of production costs and available production capacity are done by procurement and production planners. The cross-functional teams can scrutinize prototypes in the hall, select a design, and commit resources for its production and introduction in a few hours, if needed. Each commercial-sales specialist has regional expertise, as they are able to dissect tastes and customer habits through analysis of quantitative data (i.e. twice weekly order data and daily point of sales (POS) data from stores) and qualitative information communicated via voice call/meetings by store managers regarding customer reactions towards new products and customer needs i.e. desires regarding styles, materials, colors, and silhouettes requirements (Sull \& Turconi, 2008). They communicate their comprehensive understanding to the design teams at the head quarter thus helping designers keep in alignment of fast-changing trends and demands. They also provide instant feedback to the look of the new designs created by designers in terms of style, color, fabric.

Using the comprehensive information, designers get an idea of latent demand for possible fresh products that could not be identified through an automated sales-tracking system. Designers combine the comprehensive information (i.e. POS data, order data and qualitative data) along with the emerging fashion trend they perceive from discotheques, streets, movies, surveillance of clothing designs and styles chosen by opinion leaders or on successful television serials, competitor's stores, couture fashion shows, trade fairs and magazines to create new design sketch by hand and computer aided design (CAD) system (Mazaira et al., 2003; Sull \& Turconi, 2008). Using CAD system designers can make further modifications for improved matching of weaves, textures, and colors etc. (Ferdows et al., 2003). Zara's design team at its headquarter creates 40,000 items a year from which 12,000 are selected for production while key competitors would typically produce $2,000-4,000$ (Ghemawat \& Nueno, 2006). The generation of huge variety of products is possible because Zara utilizes process 
standardization in the design phase of its products through developing standardized design modules also known as vanilla box designs (Fraiman \& Singh, 2002; Pich, Hay den, \& Harle, 2002). At the start of each selling season, the designers create a library of design modules that serve as platforms also known as 'vanilla boxes' for the models that will be eventually launched. The concept design modules are stored in image format in computers and are not any kind of physical inventory (Venkatesh \& Swaminathan, 2004). Designers at Zara can comprehensively identify the latest fashion trend which is a combined result of information received from Zara stores (e.g. order data, store managers' understanding of fashion trend and POS data) and their own understanding of fashion trend they perceived through field visits discussed earlier. Designers use the identified latest fashion trend to give adaptation or customization to the library-held 'vanilla box' designs, and create nearly 5-8 new designs per day (Venkatesh \& Swaminathan, 2004). If the 'vanilla box' designs were not available to the designers, the design process could take longer time. Design by 'vanilla box' approach helps to simplify the intricacy of product variety that is innate in the fashion apparel industry and help manage the short product life cycle. Zara is an exemplar of process standardization applied at the design-manufacturing interface, so that the time point of product differentiation and production can be delayed (Venkatesh \& Swaminathan, 2004).

Ferdows et al. (2004) found that the created designs are handed over to the pattern-cutting and sample-making section or prototype shop. Skilled workers develop product prototypes manually in a couple of hours as compared to $1-2$ weeks needed by most fashion companies that outsource prototype production. In-house prototyping although costly is vital to maintain the quick velocity of design decisions. The quick pace of prototyping allows designers to experiment more flexibly with possible items. Sull \& Turconi, (2008) found that prototypes of garments-to-be are placed in the "Fashion Street"- a long parade of stores resembling the high streets of Milan or London along with rest of the collections, situated one level down beneath the $24,000 \mathrm{~m}^{2}$ design hall. Fashion Street helps design teams visualize how new products will blend into the overall picture of the company's current product offerings. Finally designs are selected for production and commercials communicate the selected items with production plants in the form of initial production order. As illustrated in Figure 1, Inditex-Zara seems to have put in place a 'product innovation laboratory' that develops a constant stream of fresh and customer-oriented products.

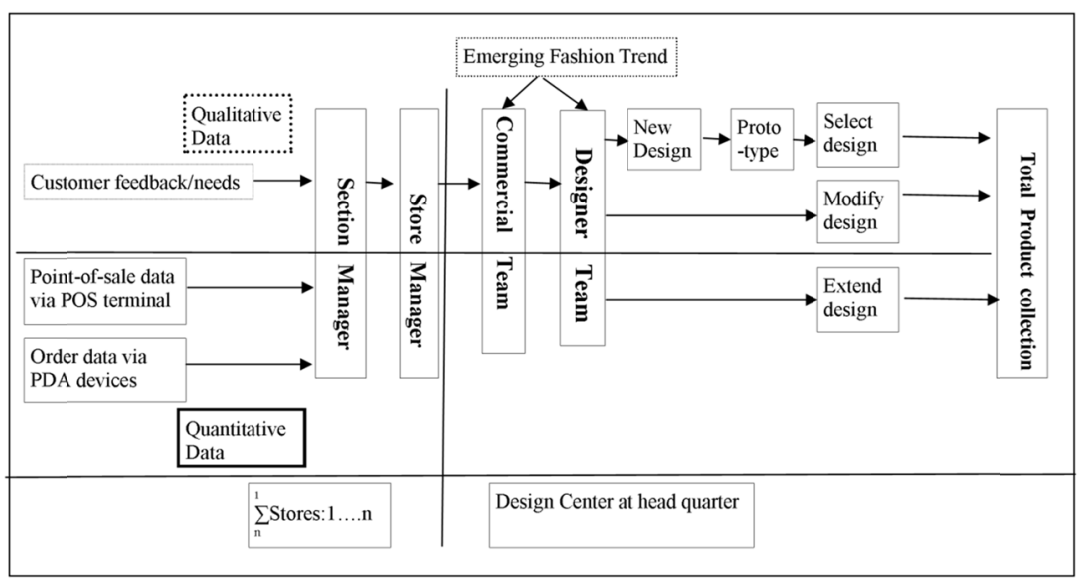

Figure 1. Design development process of total product collection

Source: Authors.

\section{Material Procurement}

Zara uses targeted volumes of aggregated fashion category apparel items to be produced in their manufacturing facilities to accurately determine their required quantity of fabrics to be purchased in advance (MacCarthy \& Jayarathne, 2009). Inaccurate estimation of quantity for fabric requirement will result in either a network that is unable to supply the required volumes because of capacity limitations or one with costly unutilized spare capacity (Christopher et al., 2004; Tyler, Heeley, \& Bhamra, 2006). Since the required lead time for fabric supply is significantly longer than garment production cycles, advance fabric purchase enables the garment production system to be separated from the longer lead time of fabric manufacturing. MacCarthy and Jayarathne (2009) noted three alternatives in the dyeing process in that, apparel product may be assembled from fabric pre-dyed by fabric manufacturers; assembled from undyed fabric subject to dyeing in retailers' own dyeing facility and 
finished garments may be dyed once assembled. Zara uses the second alternative for production of fashion category apparel items that is fabrics are bought in undyed and uncut form. Zara stores $50 \%$ of its fabrics in a 'grey' undyed state and the fabrics are later adapted into different colors by dyeing in own manufacturing facilities, after precise customer order specifications have been received (BusinessWire, 2002). This strategy enhances responsiveness by enabling them to react faster to midseason color changes (Ferdows et al., 2004). This also reduces risk since numerous styles of clothes may often be manufactured from a specific fabric type (MacCarthy \& Jayarathne, 2009; Yang \& Burns, 2003). Much of this volume is channeled via Comditel with offices located in Barcelona and Hong Kong, a 100\%-owned subsidiary of Inditex (Zara's parent company group) that manages over 932 independent suppliers of fabric and other raw materials located in Italy, Spain, Germany, Portugal, Greece and Far East. None of these suppliers account for more than $4 \%$ of Zara's total fabric requirement in order to minimize any dependency on single suppliers and encourage maximum responsiveness from them (Ferdows et al., 2003). Fabrics are delivered directly to distribution center within 5 days of orders being placed (SCM Globe, 2016). Comditel handles the dyeing, patterning, and finishing of gray fabric/cloth for all of Inditex's brands, not just Zara, and supplies finished fabric to external as well as in-house manufacturers, a process that typically takes a week (Ghemawat \& Nueno, 2006). Two of the other subsidiaries of Inditex that source fabric for Zara are both located in Hong Kong namely Inditex Asia, Ltd. and Zara Asia, Ltd. These two subsidiaries principally purchase the synthetic and fashion fabrics from suppliers located in Asia (Chu, 2005). Zara also collaborates with Fibracolor (a dyestuff producer part owned by Inditex and Zara purchases $20 \%$ of its output) to facilitate rapid changes in its printing and dyeing operations.

\section{Production Operations: Internal Manufacturing and Outsourcing}

Zara has made considerable capital investments to gain control through ownership over the production, distribution facilities and retail channels, all of which facilitates to boost the supply chain's responsiveness to new fashion trends and unpredictable demands. Zara's vertically integrated manufacturing operations enable them to constantly introduce new items to their stores in lead times as short as 15 days rather than the average 6 months needed for luxury brands (Ton, Corsi, \& Dessain, 2010). Owning production assets increases Zara's overall organizational flexibility and gives significant control over schedules and capacities that would not be possible to achieve if the company were totally reliant upon external suppliers, especially ones located in the far-east (Ferdows et al., 2004). Functional by garment type, Zara's manufacturing plants use sophisticated just-in-time manufacturing operations, developed in collaboration with Toyota, that allow the organization to customize its production operations and exploit innovations (Ferdows et al., 2004). Zara can flexibly adjust production volume of specific garments swiftly and effortlessly because it usually runs many of its plants for only a single shift. These highly automated manufacturing facilities can operate extra hours if needed to meet seasonal or unanticipated demands. Zara's ability to flexibly ramp its production up or down has a huge implication in that, product lines that did not sell well can be quickly cancelled while the popular items could be quickly replenished. Ferdows et.al, (2003) found that due to the high level of flexibility in Zara's manufacturing operations "pre-season inventory commitment"- the level of production and procurement in the supply chain for Zara is $15 \%-20 \%$ of anticipated sales versus industry average $45 \%-60 \%$. The "in-season commitments" at Zara are $40 \%-50 \%$ whereas the industry average ranges from almost zero to a maximum of $20 \%$. This helps to avoid inventory backlogs, clearance sales or inventory stock out that are a regular drain on the profit in the industry.

Internal manufacturing is performed by 11 fully owned plants, most of them positioned in and around Zara's headquarters in Arteixo, Northern Spain (Amed \& Abnett, 2015; Inditex Annual Report, 2017). These manufacturing facilities are heavily automated and perform only the capital-intensive initial production processes such as fabric dyeing; pattern design using (CAD); CAD marker making ( i.e. creating layout of pattern pieces); pattern manufacturing and fabric cutting into those patterns using automated knives or lasers aided by computer aided manufacturing (CAM). These machines can calculate how to position layout of pattern pieces on the marker efficiently and quickly on computer screens to map out the individual parts for a garment on the fabric. The machine thus minimizes fabric waste while cutting over 100 layers of cloth at single cut (Ghemawat \& Nueno, 2006; McAfee et al., 2007). The cut fabric pieces are then sent to a network of more than 400-450 partner factories located nearby the Inditex-owned factories in Galicia and Portugal to perform the labor intensive assembly/sewing operations. Zara employs about 3,000 workers in these factories performing assembly processes in Spain at an average wage rate of 8.00 euros/hour compared to average labor wage rates in Asia of about 0.40 Euros/hour (Amed \& Abnett, 2015). These partner factories/subcontractors often collect the cut pieces, along with the associated materials such as buttons and zippers in small vehicles. Zara meticulously monitor their operations to safeguard quality, conformity with labor laws, and above all else adherence to the production schedule. The relationship between Zara and its subcontractors are generally long-term and as such 
Zara collaborates with its subcontracting partners by providing technology, logistics and financial support. The partner factories then bring back the assembled items to Zara's factories, where each piece is inspected for quality control during ironing (by machine and by hand), given a machine-readable tag and packaged. The finished products are then dispatched on hangers grouped by model and size, through part of the $211 \mathrm{~km}$ network of rails to Zara's Arteixo distribution center. Completed products procured from external suppliers are also sent directly to the distribution center. Zara implements a sampling methodology to ensure quality for the incoming products (Ghemawat \& Nueno, 2006).

Zara also outsources the fashion category products to original design manufacturers (ODM suppliers) in geographically proximate countries such as Turkey, Morocco Portugal and Bulgaria that helps to compress order-to-delivery lead times (Gereffi \& Memedovic, 2003; Tokatli, 2008). "Transport time", a location factor other than the "transport cost" factor generally considered in economic geography models, allows for comparative advantages to be reassigned in favor of these geographically proximate countries (Orcao \& Pérez, 2014). Although production in these proximate sources is expensive compared to distant countries with cheaper labor wage rates, it significantly enhances flexibility. Zara can quickly cancel unpopular product lines, and avoid inventory backlogs and product markdowns that are a regular drain on profit (Tokatli, 2008). These countries have increased their competence through industrial upgradation to become ODM suppliers (Scott, 2006). The suppliers are therefore able to develop and supply designs of their own in consultation with their buyer; prepare samples and prototypes; procure fabrics and able to translate concepts into varieties of finished products; able to manufacture sophisticated high quality fashion garments and tailored suits with the required flexibility and speed; in a variety of styles in shorter runs (Tewari, 2006; Tokatli, 2008). Production in these European proximate countries is typically $15 \%-20 \%$ more expensive for Zara compared to distant Asian countries due to higher labor costs. However the attained capabilities of rapid responsiveness to demand changes in terms of volume/ variety and frequent product replenishment option for the fast fashion retailer help attain fast inventory turnaround and minimize market mediation costs which in turn counterbalances higher manufacturing labor costs (Abernathy, Dunlop, Hammond, \& Weil, 1999). Zara procures the more price-sensitive but less time-sensitive basic category apparel products by outsourcing total production processes to OEM production/full package sourcing networks located in distant sources such as China, Bangladesh, India, Pakistan, Vietnam and Cambodia where labor wage rates are lower and order-to-delivery lead times are significantly longer compared to local/proximate sourcing (Ferdows et al., 2004; Inditex Annual Report, 2005).

\subsection{Inditex's Supplier Portfolio}

Inditex works with a total of 1805 supplier situated in 53 countries. $59 \%$ of the 6959 factories Inditex works with, in total are in proximity to their headquarters in Arteixo (A Coruña, Spain), mainly in Spain, Portugal, Turkey and Morocco which also form among major production centers (Inditex Annual Report, 2016). The fashion category apparel products are sourced from these proximate factories. The rest $41 \%$ factories are located in Asian regions (e.g. China, Bangladesh, India, Pakistan, Cambodia, and Vietnam) and South-American region (e.g. Brazil and Argentina) from where basic category apparel is sourced (Ferdows et al., 2004 and Driscoll \& Wang., 2009). 50\% of all items are manufactured in its own network of Spanish factories, $26 \%$ from Europe (e.g. Portugal, Bulgaria, Lithuania, Romania) and $24 \%$ in Asia (e.g. China, India, Pakistan, Bangladesh, Cambodia, Vietnam) and Africa (e.g. Turkey and Morocco) (Amed \& Abnett, 2015). Inditex currently has 12 local dialogue platforms or geographic 'clusters' located in their sourcing regions i.e. Spain, Portugal, Morocco, Turkey, India, Pakistan, Bangladesh, Vietnam, Cambodia, China, Brazil and Argentina. These clusters encompass over $95 \%$ of Inditex's production chain (Inditex Annual Report, 2017). Each cluster is a group of stakeholders based in the same geographical region comprising of suppliers, manufacturers, trade unions, international purchasers and local Inditex CSR teams. Cluster strategy spurs collaboration between the different agents involved, significantly enhance the productivity of local manufacturers, and enable Inditex to share technology with them as a source of competitive advantage (Inditex Annual Report, 2017). Additionally, these clusters offer opportunities for cooperation with suppliers and are devised to advocate a more sustainable supply chain and production environment within a core geographic region. As such Inditex is successfully able to deploy strict social compliance and labor standards which ought to be followed by its suppliers locally and thus makes sure its suppliers' business activities have a positive impact on their communities. Inditex also joins forces with governments, non-governmental organizations (NGOs) and worker/civilian associations in order to foster engagement with its suppliers and manufacturers.

\section{Logistics and Distribution Operations}

Inditex has a total of 10 logistics centers located close to the head offices of each of its eight brands in Spain (Inditex Annual Report, 2017). The distribution center in which apparel merchandise for Zara is 
processed is located in Arteixo, A Coruña, Spain (SCM Globe, 2016). The distribution center (DC) of Inditex-Zara called "The Cube" is huge at 464,500 square meters (5 million square feet) and highly automated located in Arteixo, Northwestern Spain, along with company headquarter and 11 manufacturing facilities (Caro $\&$ Martínez-de-Albéniz, 2015). These 11 Zara owned factories are located within a $16 \mathrm{~km}$ (10 mile) radius and in addition is also connected to the distribution center with underground monorail links. These underground tunnels with high speed monorails (about 200- $211 \mathrm{~km}$ of rails) are used to transport cut fabric to these plants for dyeing and assembly into clothing items. The manufacturing plants also use the monorail system to return finished products (approximately 50,000 garments/week from each factory) to the distribution center for shipment to stores (Butler, 2013).

Inditex-Zara's competitor's regular practice is that products produced from different production points are shipped first to distribution centers to regional warehouses to individual country markets. It usually takes 2-4 weeks for Zara's competitors to transport their products from one of their distribution centers to each country market via a regional warehouse. Their underlying reason is to save transportation costs by using low cost thus slow modes of transportation and keeping a large inventory at each logistical point since they source in large quantities from each production point in order to enjoy scale economies. In addition they save their transportation costs by not overlapping or duplicating their transportation routes since they ship their products made in the local markets directly to the local distribution centers instead of shipping back to a few centralized distribution centers like Zara. On the contrary, every Inditex product regardless of its origin or destination is delivered to the allocated distribution centers of each brand in Spain, where it is picked, sorted, packed and freight loaded to be sent on to the company's global store network of those brands (Orcao \& Pérez, 2014).The clothes stay in the DC from a couple of hours to a maximum of three days since the distribution center is a point to move the merchandise rather than to store it. The objective is to manufacture and deliver only what and when the stores needed those specific items. At the distribution center, shipping of garments of exact sizes and styles as par ordered by retail stores is organized within 8 hours of a store placing an order (Chu, 2005). Inditex usually reserves $100 \%$ excess capacity in its distribution centers so as to be able to react to demand surges during the beginning of the two selling seasons in January and July or even to unexpected demand surges by boosting utilization rates of its unutilized capacity.

Mcafee, Dessain and Sjoman, (2007) noted that inside the distribution center, the most sophisticated and latest automated systems track where each SKU is stored as it enters the DC and controls the conveyor belts to pick them up and drop them off at the correct places thus allotting individual garments piece by piece depending on the needs of individual stores. The applications that control the DC's automation are developed by Inditex's IT department often in collaboration with the vendors of conveyor equipment. The garment pieces move along the carousel until they reach and fill in their allocated boxes and racks (for hanging items). These barcode marked boxes containing finished garments and each designated for individual stores are grouped and stored on the network and is called by the system when needed (Butler, 2013). These boxes leave the distribution center and are transported to a Zara's state-of-the-art logistics center (120,000-square-meter) located in Zaragoza, Northeast of Madrid, and Central Spain. This logistic center is situated proximately to the local airport and has direct connection to the railway and road network. And from there they are delivered by trucks to retail stores in Europe and by air freight to deliver clothes to distant markets twice a week (SCM Blog, 2016). Chu, (2005) noted that $20 \%-25 \%$ of Zara's products are air shipped and the rest is transported by sea freight and truck. About $65 \%$ of Zara's garments shipped are folded and 35\% are shipped hung. Hung garments are expensive to ship compared to the folded garments since they take up more volume, but this is done so that the merchandise can be delivered to the stores floor-ready. The transportation and distribution of Inditex's products to stores is undertaken entirely by external contractors (Inditex Annual Report, 2017). The deliveries reach destined stores around the world in delivery times as follows: Europe -24 hrs. United States- 48 hrs.; China- 48 hrs.; Japan-72 hrs. (Ferdows, 2004). Ferdows, (2004) stated that since all the items that are shipped to stores have already been pre-priced and tagged, store managers can put them on display the moment they come off delivery trucks, without having to iron them. The requirement for monitoring at this stage is reduced because the shipments are $98.9 \%$ accurate with less than $0.5 \%$ shrinkage. It is obvious that for Zara, speed is a paramount concern and distance is not measured in kilometers, but in time. Stores place orders and receive deliveries twice a week. Guided by inventory optimization models, each retail store gets a tailored assortment of products exactly as par ordered twice a week often within 2-4 days after order placement, depending on store location.

\section{Retailing Operations}

To rapidly match changing customer's needs, Zara practices a total control of the retail-chain through forward integration and retaining ownership of $90 \%$ of its stores (Sull \& Turconi, 2008). Zara uses franchise only in risky 
countries or in countries where wholly owned stores are not allowed to operate (Tokatli, 2008). However Zara's franchise agreements are usually designed as a 5-year contract with fees of 5-10\% of total sales and Zara always reserves the right to either buy out the franchisee or open wholly owned stores during that contract period. This arrangement allows Zara to experiment markets in new countries without bearing significant financial risk (Caro \& Martínez-de-Albéniz, 2015). During the first half of year 2017, Zara's global reach in total of 94 markets encompassed 2,236 physical stores (Inditex Annual Report, 2017). McAfee et al., (2007) stated that this allows Zara to expand its direct connection to the critical last step in the supply chain which is its customers. It is possible to install unified (POS) systems in the stores that can track real-time global sales information which gives an accurate picture of true customer demand; evolving and fast-changing customer preferences and constantly changing fashion trends in real time. Multiple POS terminals installed in a typical store transfer their respective comprehensive sales information for all SKUs performed in a typical business day to a mother POS terminal in the store. This mother POS terminal transfers the aggregated data to head quarter connected via modem. Thus Inditex is able to track real-time information on status of inventory at the precise SKU level from stores and can quickly transfer to the upstream operations of design, procurement, production, and distribution on a constant basis. This helps to mitigate the so-called 'bullwhip effect'-the tendency for fluctuations in market demand information to get exaggerated as they are transmitted back up the supply chain. A modest change in retail orders, for instance, can result in wide variation in orders as it reaches the factory while being transmitted through wholesalers and distributors (Whang \& Lee, 1998). Additionally it gives Zara more sway over retail inventories in terms of product mix, pricing and quantity offered and other factors. The level of control achieved allows Zara to set the pace at which products and information flow (Edmondson, 2003). Ton, Corsi and Dessain, (2010) stated that, stores are at the core of Zara's business model and it is where Zara constantly takes the pulse of its customer demand. Zara places the stores in prime locations that attract voluminous flow of upscale shoppers in the most high-profile commercial areas, often including landmark buildings in the premier shopping streets and upscale shopping centers around the world. The average size of the stores is 1200-1,376 square meters and carries about 40,000 units of inventory. Shop floors are designed to be spacious and therefore the product density of a typical Zara store is 28 units of inventory per square meter while traditional retailers usually have between 32 and 43 units of inventory per square meter. Ton, Corsi and Dessain,(2010) found that most of the selling space in a typical Zara store is left empty in order to create a pleasant, spacious and uncluttered shopping environment and let customers explore the products for themselves. Additionally offering fashion forward apparel in fewer quantities creates a feeling of desperation among customers. Thus when shoppers find something they like they impulsively make a purchase because the item would likely be sold out a week later. Only 70 percent of inventory is put on display at sales floor while rest 30 percent of inventory is kept in backroom. Sull and Turconi, (2008) stated that designs for store displays (i.e. looks for windows and interiors in terms of themes, color schemes, and product presentation) are centrally- designed and prototyped by teams of merchandisers at an indoor street containing model store windows located within the Arteixo headquarter. The reason for significant centralization of store layout and interior presentations of store window displays is to promote its same market image worldwide. These ideas are carried to the stores by regional teams of window dressers and interior coordinators. The shop windows are updated every 3-4 weeks. Butler, (2013) stated that Inditex spends more heavily and more frequently than key competitors in renovating and updating the layout and decor of its store base for each of its brands with new designs every 18 months. 300-400 stores are renovated per year at a cost of $€ 1.4 \mathrm{bn} / \mathrm{year}$ and thus add to one of the main areas of capital expenditure for Inditex. Attractive interior and exterior of stores provides customers with a sense of luxury and a special store experience. All of this is important for Zara as brand recognition is dependent upon store visibility. Additionally, these retail stores and word-of-mouth of customers do the advertising to draw in new shoppers. Crofton \& Dopico, (2007) stated that Zara spends relatively little on advertising ( $0.3 \%$ of sales turnover compared with $3.5 \%-5.4 \%$ by its competitors in 2001) and even does not exhibit its new merchandise at the ready-to-wear fashion shows rather are first displayed in its stores. Rather Zara spends its money on opening new stores instead of spending huge sum of money on advertising campaigns. The little ads that are undertaken are to only publicize its twice yearly sales and to announce the opening of a new store.

Inditex has taken a number of important initiatives to streamline customer's purchase process, reducing their waiting times and offer new options for buying, exchanging or returning products all of which are aimed at offering a satisfying shopping experience to consumers. First, Inditex finished implementing Radio frequency identification (RFID) technology at all its Zara stores in 2016, and aims to install it in all the stores of its other brands by 2020 (Inditex Annual Report, 2017). RFID technology allows garments to be individually identified and located quickly and with precision and increases product security from the moment they are fitted with microprocessor-based security tags at logistic platforms until the point of sale. Therefore the items and sizes that 
have been sold out on the shop floor but stock is available in the back room can be quickly detected and re-stocked in the sales floor in real time thus avoiding lost sales and maximize profits which otherwise used to be a time consuming process. RFID also forms the backbone of many other projects to improve the quality of shopping experience by customers (Inditex Annual Report, 2017). Inditex launched digital tags and interactive fitting rooms which are based upon radio frequency identification (RFID) technology. Digital tags help the sales staff in stores to match items and recommend complete outfits. This initiative also provides consumers with information about the quantity of items available in a more visual and attractive way. Interactive fitting room is installed with touch screens that offer consumers a complete shopping experience by giving them information about the products available in-store or catering the option to purchase them online. The objective of interactive fitting rooms is to reduce customers' waiting time while sales staff brings them other sizes, colors or styles when trying on the clothes. With this system, users would no longer have to leave the fitting room to find the items. Secondly, in order to offer quick and convenient access to their merchandise, Inditex is fully integrating their sales channel i.e. both brick-and-mortar and online. Under this model, customers have the choice to request in-store collection of their online purchases for free or home delivery for a fee. In cases when customers do not own a credit card, they are still able to purchase online, pay in cash and collect the merchandize from their pre-selected stores during online purchase. Finally to aid in integration of all the sales channels i.e. shopping online and in-store, Inditex worked to develop several technologies including mobile payments, quick check-out registers and mobile checkout systems. In the year of 2016, all of Inditex Group's brands implemented mobile payment system which is available from each of Inditex's eight brands' online mobile apps, as well as from Group-wide app called "In Wallet" which consolidates customer's purchases made at all of Inditex's brands. This initiative is devised to enhance customers' shopping experience, simplifying the activation process, as well as efficient handling of purchases or returns. With this system, customers simply link their bank cards to their login accounts in order to make payments by mobile phone using a highly secured QR code. Payment by mobile phones has an additional benefit in that the integrated management of online and off-line purchase receipts which are automatically saved to each customer's account are readily accessible at all times and thus simplifies the process of returning items. The system thus helps eliminate paper receipts of purchases made in stores or online. Inditex also introduced quick checkout registers which aids customers to speedily perform their purchases by themselves through streamlining the entire purchasing process. Items first need to be scanned and shown on the screen for affirmation. Customers can then pay by bank card or with their mobile device. The system can print out coupons or the original purchase receipt, which can also be saved on their phones. Inditex has also developed a mobile checkout system which allows customers to pay by mobile phone without having to go to the check-out registers.

\section{Integrated Operations of Inditex Zara}

Aftab, Yuanjian, and Kabir (2017) showed how Inditex-Zara utilizes two decoupling points namely material decoupling point and information decoupling point to apply combination of speculation/postponement strategy to perform order-driven production from semi-finished inventory rather than forecast-driven production. This is enabled by their strategic use of both process standardization (at design process and fabric sourcing process) and process resequencing for the basic products and process standardization (at design process and fabric sourcing process) for fashion products in their product line. Inditex-Zara's utilization of push-pull supply in its apparel manufacturing and supply operations significantly reduce product development and order-to-delivery lead time and ultimately removes market mediation costs for both basic and fashion category apparel products. Having discussed in details the various operations of Inditex-Zara we have developed a framework illustrating Inditex-Zara's integrated operational stages and product/information flow across the value chain in Figure 2. 




Figure 2. A framework illustrating Inditex-Zara's integrated operations and product/information flow across the value chain

Source: Modified from Mazaira, González and Ruth Avendaño, (2003); Aftab, Yuanjian, and Kabir, (2017) and Inditex Annual Report (2017).

\section{Conclusion}

The study made an attempt to make a comprehensive study of fast fashion retailer Inditex-Zara's 'world-class' supply chain practice in the apparel retailing industry. The study developed a framework illustrating Inditex-Zara's integrated operational stages and product/information flow across the value chain. For instance, first Inditex-Zara's own product development department equipped with high levell of intra-departmental collaboration is complemented with qualitative and quantitative (POS) data all collected from retail stores. These data can be accessed by product development team that results in developing a constant stream of fresh and customer-oriented products. Inditex-Zara's application of process standardization in design phase (e.g. standardized design modules), material procurement and manufacturing enable to not only launch substantially larger number of items each year but also allows postponement of product differentiation and production. This allows product adaptation into different colors and styles in very short lead time after precise customer order specifications have been received. Secondly, Zara strategically customizes its sourcing strategy according to requirements for product type. In order to attain rapid responsiveness to demand changes in terms of volume/ variety and frequent product replenishment option for fashion category apparel products, Zara performs the capital intensive manufacturing processes in-house and outsources labor intensive assembly processes to local subcontractors; and also utilizes geographically proximate ODM suppliers that are comparatively more expensive than distant and cheaper Asian suppliers. However for basic category apparel products, Zara utilizes total outsourcing from full package sourcing networks located in distant Asian countries with lower wages but longer order-to-delivery lead times. Third, Inditex-Zara has its own network of distribution centers equipped with sophisticated automated systems where products regardless of its origin or destination is delivered to for sorting, packing and freight loading to the company's logistic centers and then to global network of stores. Zara uses premium transportation mode for inbound/outbound transportation (e.g. air shipment for majority portion of fashion category apparel) and floor ready merchandise shipment to maximize speed. Forth, Zara is forward integrated through ownership of most of its retail stores. This gives total control over retail inventories in terms of product mix, pricing and quantity offered and other factors. Retail ownership allows installing unified data collection and communication technology such as POS systems in the stores to track vital information in real-time such as global sales data, customer demand/preferences, inventory status at the precise SKU level in each store. These data can be quickly transferred to the upstream operations of design, procurement, production, and distribution in a cost effective way and without delay on a constant basis. Zara's information system strongly 
supports its systematic preparation and dissemination of 'offer' and 'order' process for their highly efficient in-store merchandise inventory management. Zara's meticulous management of merchandise supply to stores combined with enhanced design, affordable price and speed contributes to successfully counter "strategic consumer behavior" which as a result significantly improves its inventory turns and lowers losses occurring from end of season markdown of unsold inventory. Inditex-Zara's integrated supply chain strategy has enabled to develop quick response capability which reduces 'bullwhip effect', order-to-delivery lead time, ensures lean inventory, and high level of supply chain responsiveness to adapt products to latest fashion trends and customer feedbacks that result in customer centric products. Inditex-Zara is able to successfully counter the negative effects of short product life cycles, high product variety, demand uncertainty and thus able to closely match product supply to the stores with market demand. This contributes to lower inventory backlogs; avoid mark-down losses and/or inventory stock out. The resulting super-responsive supply chain is able to consistently deliver products with latest fashion design to customers with rapid speed and therefore cultivate its brand image as a highly fashionable retailer. To conclude, vertical integration through ownership of various operational stages including product development, manufacturing, logistics and distribution channel; appropriate sourcing strategy to meet product needs, application of process/product modularity practices in product design, material procurement and manufacturing to ensure manufacturing flexibility; flexible logistics capability and all of these seamless integrated and coordinated by a centralized 'nervous system' or IT infrastructure can significantly raise overall supply chain flexibility and responsiveness. The study was limited to a single case study for which findings cannot be generalized. Thus statistical validation is called for by making large scale survey upon apparel retailers worldwide and also upon manufacturer-retailer organizations operating across a variety of industries such as food, consumer durables, consumer electronics, automobiles, healthcare and others to verify whether the findings and conclusions proposed in this study does actually enhance supply chain flexibility, responsiveness and competitive advantage.

\section{Acknowledgements}

This work was supported by School of Management, Wuhan University of Technology, P.R. China.

\section{References}

Abernathy, F. H., Dunlop, J. T., Hammond, J. H., \& Weil, D. (1999). A Stitch in Time: Lean Retailing and the Transformation of Manufacturing - Lessons from the Apparel and Textile Industries. Oxford University Press.

Abernathy, F. H., Volpe, A., \& Weil, D. (2006). The future of the apparel and textile industries: Prospects and choices for public and private actors. Environment and Planning A, 38(12), 2207-2232. https://doi.org/10.1068/a38114

Aftab, M., Yuanjian, Q., \& Kabir, N. (2017). Postponement Application in the Fast Fashion Supply Chain: A Review. International Journal of Business and Management, 12(7), 115.

Amed, I., \& Abnett, K. (2015). Inditex: Agile Fashion Force.

Birtwistle, G., Siddiqui, N., \& Fiorito, S. S. (2003). Quick response : perceptions of UK fashion retailers. International Journal of Retail \& Distribution Management, 31(2), 118-128. https://doi.org/10.1108/09590550310462010

Business Wire. (2002). Applied textiles selects V3 systems enterprise supply chain execution. In Business Wire.

Butler, S. (2013). Inditex: Spain's fashion powerhouse you've probably never heard of.

Caro, F., \& Martínez-de-Albéniz, V. (2015). Fast fashion: business model overview and research opportunities. In In Retail Supply Chain Management (pp. 237-264). Springer US.

Christopher, M., Lowson, R., \& Peck, H. (2004). Creating agile supply chains in the fashion industry. International Journal of Retail \& Distribution Management, 32(8), 367-376. https://doi.org/10.1108/09590550410546188

Chu, P. P. (2005). Excellence In European Apparel Supply Chains: Zara. University of Zaragoza.

Crofton, S. O., \& Dopico, L. G. (2007). Zara-Inditex And The Growth Of Fast Fashion. The Economic and Business History, 25.

Doeringer, P., \& Crean, S. (2005). Can Fast Fashion Save the US. Apparel Industry? Socio-Economic Review, 4(3), 353-377. https://doi.org/10.1093/ser/mw1014

Doeringer, P., \& Crean, S. (2006). Can fast fashion save the US apparel industry? Socio-Economic Review, 4(3), 
353-377. https://doi.org/https://doi.org/10.1093/ser/mw1014

Driscoll, M., \& Wang., P. (2009). Apparel \& footwear: retailers \& brands. Standard \& Poor's (S\&P). New York.

Eisenhardt, K. M. (1989). Building theories from case study research. Academy of Management Review, 14(4), $532-550$

Ferdows, K., Lewis, M. A., \& Machuca, J. A. D. (2004). Rapid-fire fulfillment. Harvard Business Review. https://doi.org/Article

Ferdows, K., Lewis, M., \& Machuca, J. A. D. (2003). Zara. Supply Chain Forum: International Journal, 4(2), 62-66. Retrieved

from http://search.ebscohost.com/login.aspx?direct=true \&db=buh\&AN=14517349\&site=ehost-live

Fisher, M. (1997). What is the Right Supply Chain for Your Product? Harvard Business Review, 75(2), 105-116.

Gereffi, G., \& Frederick, S. (2010). The Global Apparel Value Chain, Trade and the Crisis: Challenges and Opportunities for Developing Countries. Global Value Chains in a Postcrisis World: A Development Perspective, 157-208.

Gereffi, G., \& Memedovic, O. (2003). The Global Apparel Industry Value Chain: What Prospects for Upgrading by Developing Countries? Sectoral Studies Series 12770. United Nations Industrial Development Organization, Vienna. https://doi.org/10.2139/ssrn.424560

Ghemawat, P., \& Nueno, J. L. (2006). Zara: Fast fashion. Harvard Business School Publishing, Case No. 9.

Inditex Annual Report 2005. (2005).

Inditex Annual Report 2016. (2016).

Inditex Annual Report 2017. (2017).

Inditex Annual Report, July 2017. (2017).

J.Scott, A. (2006). The Changing Global Geography of Low-Technology, Labor-Intensive Industry: Clothing, Footwear, and Furniture. World Development, 34(9), 1517-1536.

MacCarthy, B., \& Jayarathne, P. G. S. (2009). Fast Fashion: Achieving Global Quick Response (GQR) in the Internationally Dispersed Clothing Industry. SSRN Electronic Journal, 37-60. https://doi.org/10.2139/ssrn.1360684

Mazaira, A., González, E., \& Avendaño, R. (2003). The role of market orientation on company performance through the development of sustainable competitive advantage: the Inditex-Zara case. Marketing Intelligence \& Planning, 21(4), 220-229.

McAfee, A., Sjoman, A., \& Dessain, V. Zara: IT for Fast Fashion (2007).

McCutcheon, D. M., Raturi, A. S., \& Meredith, J. (1994). The customization-responsiveness squeeze. Sloan Management Review, 35(2), 89-99.

Mintzberg, H. (1979). An emerging strategy of" direct” research. Administrative Science Quarterly, 24(4), 582-589.

Omera, K., Christopher, M., \& Creazza, A. (2012). Aligning product design with the supply chain: A case study. Supply Chain Management: An International Journal, 17(3), 323-336. https://doi.org/10.1108/13598541211227144

Orcao, A. I. E., \& Pérez, D. R. (2014). Global production chains in the fast fashion sector , transports and logistics: the case of the Spanish retailer Inditex Los transportes y la logística en las cadenas globales de producción del sector de la moda rápida : el caso de la empresa española In. Investigaciones Geográficas: Boletín Del Instituto de Geografia, 2014(85), 113-127. https://doi.org/10.14350/rig.40002

Pich, M., Hay Den, L., \& Harle, N. M. \& Spencer (2012). Zara: Process Competition inthe Textile Apparel Industry.

SCM Globe. (2016). Zara Clothing Company Supply Chain.

Sull, D., \& Turconi, S. (2008). Fast fashion lessons. Business Strategy Review, 19(2), 4-11. https://doi.org/10.1111/j.1467-8616.2008.00527.x

Tewari, M. (2006). Adjustment in India's textile and apparel industry: reworking historicallegacies in a post-MFA world. Environment and Planning A, 38, 2325-2344. 
Tokatli, N. (2008). Global sourcing: Insights from the global clothing industry - The case of Zara, a fast fashion retailer. Journal of Economic Geography, 8(1), 21-38. https://doi.org/10.1093/jeg/lbm035

Ton, Z., Corsi, E., \& Dessain, V. (2010). Zara: Managing Stores for Fast Fashion.

Tyler, D., Heeley, J., \& Bhamra, T. (2006). Supply chain influences on new product development in fashion clothing. Journal of Fashion Marketing and Management, 10(3), 316-328. https://doi.org/10.1108/13612020610679295

Venkatesh, S., \& Swaminathan, J. M. (2004). Managing Product Variety Through Postponement: Concept and Applications. In The Practice of Supply Chain Management: Where Theory and Application Converge (pp. 139-155). https://doi.org/10.1007/0-387-27275-5_9

Warburton, R. D. H., \& Stratton, R. (2002). Questioning the relentless shift to offshore manufacturing. Supply Chain Management: An International Journal, 7(2), 101-108. https://doi.org/10.1108/13598540210426659

Whang, S., \& Lee, H. (1998). Value of postponement, in Product Variety Management: Research Advances. In $T$. Ho and C.S. Tang (eds.), Kluwer Academic Publishers, Boston, MA (pp. 66-84).

Yang, B., \& Burns, N. (2003). Implications of postponement for the supply chain. International Journal of Production Research, 41(9), 2075-2090.

Yin, R. (2003). Case study research: Design and methods. Sage Publications, Inc, 5(11).

Yin, R. K. (2004). The case study anthology. Sage.

Yin, R. K. (2009). How to do better case studies. The SAGE Handbook of Applied Social Research Methods, 2 , 254-282.

\section{Copyrights}

Copyright for this article is retained by the author(s), with first publication rights granted to the journal.

This is an open-access article distributed under the terms and conditions of the Creative Commons Attribution license (http://creativecommons.org/licenses/by/4.0/). 